because a comfortable and privileged clinician decides that the experience was not rare enough or nasty enough?

Lillywhite \& Neal also complain that "PTSD is a condition which presents with a wide spectrum of severity". Surely there is not condition that cannot present with a wide spectrum of severity? Assessment of the severity of the condition is routine, but not inevitably part of the diagnosis. They urge the use of one particular scale out of several available, because it includes a severity scale. There is no compelling evidence favouring the CAPS-1 scale over other PTSD measures. Earlier reliable and valid scales were to some extent outdated by the changes introduced in DSM-III-R, but other current measures, such as the PTSD Symptom Scale (PSS; Foa et al, 1993), also include severity measures; scales which do not can be supplemented by assessment of severity. Psychometric instruments which essentially merely ask whether the criteria for DSM PTSD are present can be valid indicators of the presence of PTSD without much risk of being interesting or of adding much to our knowledge. The possible value of instruments using dichotomous and continuous scales, which they suggest, has long been recognised (e.g. Weisenberg et al, 1987).

Lillywhite \& Neal refer to finding "marked clinical improvement" due to simple assessment (a therapeutically trivial intervention). This is so much at variance with experience of PTSD as to raise doubts about the diagnosis and severity of the cases to which they refer, and if these findings, which they report devoid of detail, are sound, they should publish them as soon as possible, and in full detail.

They would have been more justified in challenging the evidence for the efficacy of the eyemovement desensitisation technique reported by Specor \& Huthwaite. No plausible rationale has been offered for this therapy, while sensational claims are made, and it is being widely marketed and taught before adequate convincing and scientifically sound studies have established its efficacy. Metter \& Michelson (1993), among others, have raised doubts about such excessive claims; and report a study in which the results of eye-movement desensitisation were not significantly different from those of control conditions, and "possibly less efficacious than having subjects stare at a dot on the wall."

EPSTEIN, R.S. (1993) Avoidant symptoms cloaking the diagnosis of PTSD in patients with severe accidental injury. Journal of Traumatic Stress, 6, 451-458.
Feinstein, A. \& Dolan, R. (1991) Predictors of post-traumatic stress disorder following physical trauma: an examination of the stressor criterion. Psychological Medicine, 21, 85-91.

FoA, E.B., Rigos, D.S., DANCU, C.V., et al (1993) Reliability and validity of a brief instrument for assessing post-traumatic stress disorder. Journal of Traumatic Stress, 6, 459-473.

MARCH, J.S. (1993) What constitutes a stressor? The "Criterion A" issue. In Posttraumatic Stress Disorder: DSM-IV \& Beyond (eds J.R.T. Davidson \& E.B. Foa), pp. 37-54. Washington: American Psychiatric Press.

Metter, J. \& Michelson, L.K. (1993) Theoretical, clinical, research and ethical constraints of the eye movement desensitization reprocessing technique. Journal of Traumatic Stress, 6, 413-415.

SimPSON, M.A. (1993) Traumatic stress and the bruising of the soul: The effects of torture and coercive interrogation. In The International Handbook of Traumatic Stress Syndromes (eds J.P. Wilson \& B. Raphael), pp. 667-684, New York: Plenum Press. Weisenderg, M., Solomon, Z., Schwarzwald, J., et al (1987) Assessing the severity of posttraumatic stress disorder: relation between dichotomous and continuous measures. Journal of Consulting and Clinical Psychology, 55, 432-434.

Michael A. Simpson

Centre for Psychosocial and Traumatic Stress

Pretoria Department of Psychiatry

Medical University of South Africa

\section{Diogenes syndrome by proxy}

SIR: There has been considerable interest in factitious disorders both in the lay press and among psychiatric nosologists in the preparation of DSM-IV. This interest has focused mainly on Munchausen syndrome and Munchausen syndrome by proxy. Diogenes syndrome, which refers to a state of marked self-neglect, domestic squalor and disorder, hoarding rubbish and social isolation, is well described since the term was first used by Clark et al (1975). However, a factitious disorder involving the classic features of Diogenes syndrome by proxy has not been described. We now report such a case.

Case report. An 81-year-old woman was referred by her general practitioner for in-patient assessment of mobility, having been bed-bound for two weeks following a fall. The fall resulted from poor sight due to senile macular degeneration. She also suffered from a chronic anxiety state, and she had complained of "low spirits".

The patient was moderately anxious, had faecal impaction and impaired visual acuity, but was independently mobile with the aid of a walking frame. She complained that during the two weeks of being bed-bound she had been neglected by her 48 -year-old daughter, who had lived with the patient for the previous year. The patient alleged having been deprived of regular food, clean bed linen and assistance with getting to the toilet, resulting in double incontinence. On further questioning, it became clear that the patient's immobility was compounded by physical obstruction of her pathway from her bed to the bathroom 
by piles of newsprint and cardboard. This situation had only come about after her daughter had moved from her own accommodation to the patient's two-bedroomed flat. A collateral history from the patient's community medical social worker and general practitioner confirmed the patient's account of enforced domestic squalor for the previous year. The daughter's problem with hoarding of rubbish had been present over 20 years, resulting in a state of such clutter in her own flat as to make it uninhabitable. This had led to her taking up residence with her mother. She had no insight into her hoarding problem, seeing this as reasonable behaviour.

Diogenes syndrome by proxy is a clear example of 'elder abuse', although it may be unintentional as in this, the first described case. The aetiology in this case is unknown, as the patient's daughter has never had a formal psychiatric evaluation. Diogenes syndrome is usually encountered in persons over 60 years (Macmillan \& Shaw, 1966; Clark et al, 1975), but it is recognised in younger patients in association with chronic alcoholism, chronic paranoid schizophrenia, and major affective disorder (Berlyne, 1975). The problem may be insidious, escaping recognition and being incorrectly ascribed to eccentric behaviour or senile dementia in an elderly person. Absence of physical injury may obscure the diagnosis of Diogenes syndrome by proxy. As in the case of Munchausen syndrome by proxy, very young or elderly dependants of patients with documented or suspected Diogenes syndrome must be considered at risk of Diogenes syndrome by proxy, even when the patient lives alone, which is the case with most patients with Diogenes syndrome (Cybulska \& Rucinski, 1986).

BERLYNe, N. (1975) Diogenes syndrome. Lancet, $i, 515$.

Clark, A.N.G., Mankikar, G.D. \& Gray, I. (1975) Diogenes syndrome. A clinical study of gross neglect in old age. Lancet, $i$. 366-368.

CYBulSKa, E. \& Rucinski, J. (1986) Gross self-neglect in old age. British Journal of Hospital Medicine, 36, 21-25.

Macmillan, D. \& Shaw, P. (1966) Senile breakdown in standards of personal and environmental cleanliness. British Medical Journal, ii, 1032-1037.

Denis O'MAHONY J. Grimley Evans

Department of Clinical Geratology

Radcliffe Infirmary

Woodstock $R d$

Oxford $O X 26 H E$

\section{How abuse has affected me}

$A$ is now 22 years old and has received at least four periods of in-patient treatment, having been on an acute ward for the last year. She is a self-mutilator who has a long history of sexual abuse.
She has not been able to confide in male members of staff but did, with encouragement, take a BTech course. As part of that course she submitted a dissertation on her abuse, obtaining a distinction for her work.

As our therapeutic partnership progressed, she was eventually able to let me read this dissertation, and I was particularly intrigued by the passage which is given below. I find it poignant and thought provoking and, with A's permission, am happy to share her observations with you.

I make no comment as to the content and meaning of her words, and hope that you will be able to gain as much insight from her observations as I have.

"My name is [A] and I am twenty two years old. I suffered physical and sexual abuse from the age of three until I left home at seventeen years of age.

\section{How ABUSE has affected ME}

"I am ANGRY with myself / I do not like being looked at / I don't trust myself or others - men / I BLAME MYSELF / I feel DIRTY and GUILTY / I am a perfectionist / I am afraid of bathing and swimming / I feel paranoid / I have poor self respect / I am self conscious / I feel INFERIOR / I am SCARED of relationships / I am scared of being touched / I feel UNWORTHY / I don't like silence / I have agoraphobia / I feel WITHDRAWN / I am overprotective - of children / I don't like wearing clothes in case they get dirty / I don't wear skirts, only trousers / I wear dark clothes / I am AFRAID to be alone with a man / I feel I should HARM myself / I like to be poorly - for attention / I don't feel creative / I am highly strung / I feel edgy / I am DEFENSIVE/I lack self-confidence $/$ I have NIGHTMARES and flashbacks / I hear voices / I have hallucinations / I find situations DANGEROUS / I have amnesia.

Stanley Royd Hospital Wakefield

STEPHEN H. ShaW

\section{Estimates of risks in relatives of psychotic probands}

SIR: There is compelling evidence that genetic factors are important in determining susceptibility to schizophrenia (Gottesman, 1990). Knowledge of the lifetime risks of schizophrenia in the general population and in various classes of relatives of 